\title{
Chlorine dioxide disinfection of single and dual species biofilms, detached biofilm and planktonic cells
}

\section{Authors: Sabrina Behnke \& Anne Camper}

NOTICE: This is an Accepted Manuscript of an article published in Biofouling on July 2012, available online: http://www.tandfonline.com/10.1080/08927014.2012.700705.

Behnke S, Camper AK, "Chlorine dioxide disinfection of single and dual species biofilms, detached biofilm and planktonic cells," Biofouling: The Journal of Bioadhesion and Biofilm Research, July 2012 28(6):635-647

Made available through Montana State University's ScholarWorks 


\title{
Chlorine dioxide disinfection of single and dual species biofilms, detached biofilm and planktonic cells
}

\author{
Sabrina Behnke ${ }^{\mathrm{a}}$ and Anne K. Camper ${ }^{\mathrm{a}, \mathrm{b}_{*}}$ \\ ${ }^{a}$ Center for Biofilm Engineering, Montana State University, Bozeman, MT 59717, USA; ${ }^{b}$ Department of Civil Engineering, Montana State \\ University, Bozeman, MT 59717, USA
}

\begin{abstract}
Disinfection efficacy testing is usually done with planktonic cells or more recently, biofilms. While disinfectants are much less effective against biofilms compared to planktonic cells, questions regarding the disinfection tolerance of detached biofilm clusters remain largely unanswered. Burkholderia cepacia and Pseudomonas aeruginosa were grown in chemostats and biofilm tubing reactors, with the tubing reactor serving as a source of detached biofilm clusters. Chlorine dioxide susceptibility was assessed for B. cepacia and $P$. aeruginosa in these three sample types as monocultures and binary cultures. Similar doses of chlorine dioxide inactivated samples of chemostat and tubing reactor effluent and no statistically significant difference between the $\log 10$ reductions was found. This contrasts with chlorine, shown previously to be generally less effective against detached biofilm particles. Biofilms were more tolerant and required chlorine dioxide doses ten times higher than chemostat and tubing reactor effluent samples. A second species was advantageous in all sample types and resulted in lower $\log _{10}$ reductions when compared to the single species cultures, suggesting a beneficial interaction of the species.
\end{abstract}

Keywords: chlorine dioxide; disinfection; biofilm; detached biofilm; Burkholderia cepacia; Pseudomonas aeruginosa

\section{Introduction}

When bacteria become attached to surfaces in suitable aqueous environments, they proliferate and form microcolonies that eventually develop into biofilms. These bacterial communities produce extracellular polymeric substances (EPS) as a protective layer and are highly heterogeneous in their composition with regard to gene expression and nutrient requirements (Donlan and Costerton 2002; Davies 2003). Biofilms are much more tolerant to antibiotic and disinfectant treatment than planktonic cells partially due to the production of EPS material that serves as a protective layer which physically holds cells together but can also reactively deplete the chemicals and retard their diffusion to the cells (DeBeer et al. 1994: Donlan and Costerton 2002; Davies 2003; Steed and Falkingham 2006). In addition, it has been shown that biofilm cells express different protein profiles than planktonic cells and also display different growth rates as a result of limited nutrient and oxygen availability that can make them more tolerant (Walters et al. 2003 ; Rani et al. 2007).

In mixed species biofilms bacteria inhabit suitable niches in a particular microenvironment and may undergo symbiotic relationships between the different species (Møller et al. 1996, 1998). It has been suggested that cell to cell signaling in multispecies biofilms increases disinfection tolerance by boosting transcrip-tion of genes responsible for survival of oxidative stress (Loewen and Hengge-Aronis 1994), altering the composition and viscosity of the EPS (Burmølle et al. 2006), or influencing biofilm architecture and the spatial distribution of different strains (Cowan et al. 2000; Nielsen et al. 2000). These quorum sensing induced mechanisms enable bacteria to react to environmental challenges such as oxidative stress in a coordinated manner.

Additionally, environmental changes may trigger detachment of cells and clusters as part of the biofilm life cycle to guarantee survival of the community when conditions are no longer suitable for proliferation (Sauer et al. 2002; Hunt et al. 2004). Passive forms of detachment can occur when shear stress increases or certain chemicals alter the cohesion of the EPS (Simo es et al. 2005, 2008; Davison et al. 2010). A wide range of cluster sizes detaches from biofilms, from single cells to large clusters containing more than 1000 cells while the proportions are dependent on the species composition and the growth conditions of the biofilm (Wilson et al. 2004; Behnke et al. 2011).

Detached clusters may behave similarly to biofilms when exposed to disinfectants especially shortly after 
the detachment event. When returned to the bulk fluid, clusters may eventually shift back to protein expression profiles characteristic of planktonic growth when conditions are suitable (Rollet et al. 2009). These detached cells and clusters are of concern because they may survive disinfection challenges due to neutralization or complete consumption of the disinfectant by EPS constituents, followed by re-attachment on suitable surfaces downstream to continue growth (Costerton et al. 1995). Disinfectant doses used to kill planktonic free floating cells may not be sufficient to disinfect cells within detached biofilm clusters (Fux et al. 2004; Steed and Falkinham 2006).

Biofilm control often is performed using a strong oxidizing agent such as chlorine, ozone or chlorine dioxide. While chlorine is inexpensive and commonly used in a variety of industrial settings, chlorine dioxide, with high oxidation capability, has been described to be more effective than chlorine against biofilms (Mayack et al. 1984). In potable and waste water treatment applications, a number of researchers have commented on the significantly lower demand of the water for chlorine dioxide than for chlorine (Ridenour and Ingols 1947; Ingols and Ridenour 1948). Chlorine dioxide has been described to be more selective in polluted samples since it does not react with every compound that can be oxidized, but is more specific to organic compounds (Hoigné and Bader 1994). Benarde et al. (1967) reported that chlorine dioxide might specifically act against the protein synthesis of bacteria by attacking amino acids bonds. Jang et al. (2006) reported that chlorine dioxide at $25 \mathrm{ppm}$ was able to penetrate biofilms up to $100 \mu \mathrm{m}$ in thickness which suggests more effective killing for thinner biofilms.

The goal of this study was to determine the differential efficacy of chlorine dioxide against bacterial monocultures and co-cultures of environmental isolates $P$. aeruginosa (RB-8) and $B$. cepacia (FS-3). Co-culture of both strains is thought to be beneficial to the survival of the cells during treatment due to physical interactions or physiological adaptations of the two species. The EPS matrix may change with respect to diffusional properties or viscosity due to the presence of a second species in the biofilm caused by a shift in gene expression patterns. Other mechanisms that have been observed in multi-species biofilms are the conjugative transfer of tolerance factors (Ghigo 2001) and the protection of one species through the close spatial association with the other species (Cowan et al. 2000). Cultures grown as planktonic cells, biofilms, and detached biofilm clusters harvested from the biofilm effluent were tested and log reductions compared. Chlorine dioxide as a strong oxidizer has been demonstrated to act more specifically on cells and electron-rich centers of organic molecules and is thought to be especially effective against biofilms (Benarde et al. 1967; Mayack et al. 1984) which leads to the belief that chlorine dioxide at low concentrations will effectively disinfect biofilm samples, as well as rapidly inactivate planktonic cells and detached biofilm clusters.

\section{Materials and methods}

Two different standardized reactors were used to determine the chlorine dioxide tolerance of planktonic cells, cells detached from biofilm, and the attached biofilm. Environmental isolates of Burkholderia cepacia (FS-3) and Pseudomonas aeruginosa (RB-8) were grown as monocultures and mixed cultures in chemostats and biofilm tubing reactors.

Disinfection effectiveness was assessed for all sample types (chemostat, tubing reactor effluent, attached biofilm, and homogenized control samples) and all species scenarios (single FS-3, single RB-8, binary culture) and $\log _{10}$ reductions were compared. Additionally, the disinfection rates for all sample types and species scenarios were calculated by recording $\log _{10}$ reductions at various time points during disinfection.

\section{Bacterial cultures and nutrient medium}

Cultures for the inoculation of reactors were grown overnight on a shaker in a low nutrient sterile defined medium consisting of $0.1 \mathrm{~g} \mathrm{l}^{-1}$ glucose, $0.018 \mathrm{~g} \mathrm{l}^{-1}$ $\mathrm{NH}_{4} \mathrm{Cl}, 3.93 \mathrm{~g} \mathrm{l}^{-1}$ phosphate buffer $\left(2.71 \mathrm{~g}^{-1} \mathrm{Na}_{2}\right.$ $\left.\mathrm{HPO}_{4} ; 1.22 \mathrm{~g} \mathrm{l}^{-1} \quad \mathrm{KH}_{2} \mathrm{PO}_{4}\right)$, and $2 \mathrm{ml} \mathrm{l}^{-1} 0.1 \mathrm{M}$ $\mathrm{MgSO}_{4}$ (Fisher Scientific, Pittsburgh, PA) at room temperature $\left(22 \pm 2^{\circ} \mathrm{C}\right)$. The maximum growth rates of $B$. cepacia FS-3 and $P$. aeruginosa RB-8 in the defined medium were $0.20( \pm 0.02) \mathrm{h}^{-1}$ and 0.17 $( \pm 0.02) h^{-1}$, respectively.

\section{Planktonic cells from the chemostat}

The chemostat (BioSurface Technologies Corp., Bozeman, Mont.) with a volume of $170 \mathrm{ml}$ and a residence time of just over $6 \mathrm{~h}$ was run using a nutrient flow of $0.5 \mathrm{ml} \mathrm{min}{ }^{-1}$. The chemostat was filled with the defined medium mentioned above and then inoculated with $3 \mathrm{ml}$ of the $18 \mathrm{~h}$ overnight cultures $(1.5 \mathrm{ml}$ of each strain for dual culture inoculation). Batch mode (no flow) for $\sim 2$ residence times ( $12 \mathrm{~h}$ ) was followed by continuous flow for another $\sim 6$ residence times $(36 \mathrm{~h})$ to reach a steady state of the planktonic culture. To reduce biofilm formation on the walls of the chemostat, the operation time was limited to $48 \mathrm{~h}$. The lid of the chemostat was removed for collection of a sample after the flow was turned off. 


\section{Biofilm reactor}

Sterile, autoclaved silicone tubing with length of $45 \mathrm{~cm}$ and an inner diameter of $0.31 \mathrm{~cm}$ (ColeParmer Masterflex Size 16 peroxide-cured silicone tubing, reactor volume $3.4 \mathrm{ml}$ ) was filled with nutrient medium and then inoculated with $2 \mathrm{ml}$ of overnight culture (1 $\mathrm{ml}$ of each strain for dual culture) using a sterile syringe and needle. The tubing reactor was run with a flow of $0.5 \mathrm{ml} \mathrm{min}{ }^{-1}$ and a residence time of $6.8 \mathrm{~min}$ which was much lower than the doubling time of the two strains and thus avoided the possibility of a planktonic culture in the bulk fluid of the reactor. After inoculation, the cells were allowed to attach to the walls of the tubing for $3 \mathrm{~h}$, under no flow, followed by growth for 4 days under flow conditions at room temperature $\left(22 \pm 2^{\circ} \mathrm{C}\right)$.

\section{Sampling of detached clusters and cells from the biofilm reactor}

For sampling of detached cells and clusters, the nutrient medium was switched to buffer (defined low nutrient medium without $\mathrm{NH}_{4} \mathrm{Cl}$ and glucose) immediately before samples were taken. This was necessary to prevent chlorine dioxide decay and the production of any organic chlorine compounds that could impact the disinfection process. The waste carboy was detached from the tubing reactor and reactor effluent was collected in a sterile falcon tube (Becton Dickinson, Franklin Lakes, NJ) and kept on ice. Samples were handled carefully to avoid disruption of clusters.

\section{Sampling of attached biofilm from the biofilm reactor}

Before destructively sampling the biofilm tubing reactor, the exposed outside of the silicone tubing was disinfected with ethanol for several minutes. Then, the reactor was disconnected and the remaining nutrient medium in the reactor was discarded. Individual pieces of tubing were cut to desired length (1 to $1.5 \mathrm{~cm}$ ) and submerged into $10 \mathrm{ml}$ of chilled buffer prior to disinfection treatment or quantification. Attached biofilm was removed from the tubing for plate counting of controls and biofilm disinfection experiments. With the help of sterile forceps, biofilm was extruded from the silicone tubing and returned to the buffer for pulse-vortexing $(1 \mathrm{~min})$ followed by removal of the tubing and shear homogenization $(20,500 \mathrm{rpm}, 1 \mathrm{~min})$ of the detached biofilm (shear homogenizer, IKA Labortechnik, Staufen, Germany).

The thicknesses of these biofilms were previously determined and found to be $26 \mu \mathrm{m}( \pm 4 \mu \mathrm{m})$ for FS-3, $28 \mu \mathrm{m}( \pm 4 \mu \mathrm{m})$ for RB-8 and $23 \mu \mathrm{m}( \pm 4 \mu \mathrm{m})$ for the dual species (Behnke et al. 2011).

\section{Homogenization}

Aliquots of the planktonic, tubing reactor effluent and biofilm samples were shear homogenized (shear homogenizer, IKA Labortechnik, Staufen, Germany) at $20,500 \mathrm{rpm}$ for $1 \mathrm{~min}$ prior to disinfection, for comparison with intact clusters. The homogenizer was sterilized between samples by flaming with ethanol. Data on the characteristics of homogenized vs nonhomogenized samples can be found in Behnke et al. (2011).

\section{Chlorine dioxide disinfection}

Chlorine dioxide tablets (Aseptrol ${ }^{10} \mathrm{~S} 10-\mathrm{Tab}$, provided by BASF) were used as a source for dissolved chlorine dioxide gas. A new stock (1 tablet in $200 \mathrm{ml}$ of nanopure water) was prepared daily and the concentration was measured at $360 \mathrm{~nm}$ (molar absorption coefficient $=12501 \mathrm{~mol}^{-1} \mathrm{~cm}^{-1}$ ) using a Genesys spectrophotometer (Gauw et al. 1999). For the direct measurement, small aliquots of the chlorine dioxide solution were transferred to cuvettes and measured for absorbance. In the range of chlorine dioxide concentrations used in these experiments $(0.5-10 \mathrm{ppm})$ the method generated linear standard curves with an average $\mathrm{R}^{2}$ of 0.999 . This method was found to be the most appropriate for this system in side-by-side comparisons with other analytical approaches (data not shown).

Chlorine dioxide concentrations were verified via standard curves and added to the samples in incrementally increasing amounts until no survivor colonies were visible on agar plates with the $0^{\text {th }}$ dilution.

Initial $\log _{10}$ numbers of the planktonic cells and detached particles were standardized to $7.0 \log _{10}$ (CFU $\mathrm{ml}^{-1}$ ) by dilution with sterile buffer before exposure to chlorine dioxide. This was accomplished by enumerating the number of cells in the chemostat and the detached particle samples by serial dilution and drop plating ( $\mathrm{n} \geq 3$ ) on $\mathrm{R} 2 \mathrm{~A}$ agar. The dilution factor was then calculated to standardize the initial cell numbers to $7.0 \log _{10} \mathrm{CFU} \mathrm{ml} \mathrm{m}^{-1}$ for each disinfection experiment.

Attached biofilm was standardized by choosing the suitable length of tubing (1 to $1.5 \mathrm{~cm}$ ) that resulted in $\sim 7.0 \log _{10}$ (CFU ml ${ }^{-1}$ ) after homogenization in $10 \mathrm{ml}$ of buffer. The $\log _{10}$ densities of attached biofilm are therefore also expressed in $\mathrm{CFU} \mathrm{ml} \mathrm{m}^{-1}$. With this approach initial cell number comparison to $\mathrm{CFU} \mathrm{ml} \mathrm{m}^{-1}$ from the chemostat and detached cells/clusters was straightforward.

After addition of the initial dose of chlorine dioxide, samples were exposed for $30 \mathrm{~min}$ or other time points as designated in a shaking incubator at room temperature $\left(22 \pm 2^{\circ} \mathrm{C}\right)$ along with untreated control samples in clean glassware with minimal 
oxidant demand (data not shown). At the end of $30 \mathrm{~min}$, no measurable chlorine dioxide remained in the samples where the cells were added. Regardless of this, samples $(10 \mathrm{mI})$ were neutralized by adding $100 \mu \mathrm{l}$ of $6 \mathrm{~N}$ sodium thiosulfate (Fisher Scientific, Pittsburgh, PA). Control experiments demonstrated no effect of neutralization on the culturability of either species (data not shown).

\section{Bacterial counts}

Serial dilutions in sterile $\mathrm{pH} 7.41 \times$ PBS buffer $(8 \mathrm{~g}$ of $\mathrm{NaCl}, 0.2 \mathrm{~g}$ of $\mathrm{KCl}, 1.44 \mathrm{~g}$ of $\mathrm{Na}_{2} \mathrm{HPO}_{4}$, and $0.24 \mathrm{~g}$ of $\mathrm{KH}_{2} \mathrm{PO}_{4}$ suspended in 11 of purified water, chemicals by Fisher Scientific, Pittsburg, PA) were carried out prior to plating on R2A plates (Difco ${ }^{\mathrm{TM}}$ R2A Agar, BectonDickinson, Franklin Lakes, NJ) using the drop plate method (Herigstad et al. 2001). Agar plates were incubated for $48 \mathrm{~h}$ at $30^{\circ} \mathrm{C}$. Colony appearance allowed for visual discrimination of the two strains on R2A plates. $P$. aeruginosa produced larger (compared to $B$. cepacia) colonies that were yellowish-green and glossy. B. cepacia colonies were smaller, very defined white-yellowish colonies.

Total inactivation was defined as the concentration that resulted in the absence of any colony forming units (CFU) in the undiluted treated sample $\left(0^{\text {th }}\right.$ dilution). If no CFU were present on the drops on the R2A plates, a 1 was substituted for one of the drops and then averaged over 3 drops (EPA guidance for data quality assessment QA/G-9, section 4.7, 1998).

\section{Broken line regression/calculation of inactivation rate constants ( $k$ values)}

Additional disinfection experiments were done with subjectively chosen sub-lethal doses of chlorine dioxide and sampled after 1, 2, 5, 10, 20, and $30 \mathrm{~min}$, neutralized and plated to calculate inactivation rate constants. Inactivation curves were generated in Microsoft Excel by plotting the $\ln \left(\mathrm{CFU} \mathrm{ml} \mathrm{m}^{-1}\right)$ that survived the treatment vs time. Due to the bi-phasic behavior of the disinfection curves, $\mathrm{k}$ values were calculated for the first minute and also for disinfection times from 2 to $30 \mathrm{~min}$. For $\mathrm{k}$ values with multiple time points (at least 3), a regression line was fit to $\ln (\mathrm{N})$ to obtain a slope ' $\mathrm{m}$ ' and an intercept $\ln \left(\mathrm{N}_{0}\right)$. The $\mathrm{k}$ value was subsequently found by setting $\mathrm{k}=-\mathrm{m} / \mathrm{C}$. Chick (1908) described killing curves with

$$
\mathrm{k}=-\ln \left(\mathrm{N} / \mathrm{N}_{0}\right) / \mathrm{C} * \mathrm{t}
$$

where $\mathrm{N}_{0}$ ' is the initial CFUml ${ }^{-1}$ and ' $\mathrm{N}$ ' is the $\mathrm{CFUml}^{-1}$ after time ' $\mathrm{t}$ ', and ' $\mathrm{C}$ ' is the initial concentration of disinfectant.

\section{Statistical analysis}

For each pairwise species comparison (FS-3 vs RB-8; FS-3 vs dual FS-3, RB-8 vs dual RB-8), an ANOVA was fit with reactor, species and chlorine dioxide dose (reactor and species only for initial $\log _{10}$ densities) as factors. To account for the pairing of the dual FS-3 and dual RB-8 species grown in the same reactor, the difference between the $\log _{10}$ reductions (LRs) of the two strains were calculated for each reactor, and an ANOVA with reactor and dose was fit to these differences. This same paired analysis was used to compare homogenized and unhomogenized samples which were collected from the same reactor. To compare the LDs of the biofilm controls of the two species in a dual culture, a paired t-test was performed.

Inactivation rates ( $\mathrm{k}$ values) were compared pairwise (FS-3 vs RB-8; FS-3 vs dual FS-3, RB-8 vs dual RB-8) by performing an ANOVA with reactor and species as factors. The pairing of dual FS-3 and dual RB-8 was accounted for by calculating the differences between these $\mathrm{k}$ values and an ANOVA was fit to these differences. All of the ANOVA models were fit in Minitab $^{10}$ (Version 16). The follow-up t-tests and the weighted least squares were performed in $\mathrm{R}$ (version 2.11.0).

The analyses described above were divided into seven categories for control of the false discovery rate: the LRs for FS-3 vs RB-8; FS-3 vs dual FS-3; RB-8 vs dual RB-8; dual FS-3 vs dual RB-8; homogenized vs unhomogenized; $\mathrm{k}$ values; and $\mathrm{k}$ values of homogenized samples. A Benjamini-Hochberg correction (Benjamini and Hochberg 1995) was applied to each of these seven groups to maintain the false discovery rate at $5 \%$. Claims of statistical significance were made with respect to this correction, although the p-values reported are un-adjusted.

\section{Results}

In this study the differential efficacy of chlorine dioxide against bacterial monocultures and co-cultures of $P$. aeruginosa RB-8 and B. cepacia FS-3 was determined. Cultures grown as planktonic cells, biofilms, detached biofilm clusters harvested from the biofilm effluent and homogenized samples were tested and log reductions were compared. Additionally, disinfection rates were calculated for each sample type and species scenario.

\section{Initial cell numbers and species distribution in co-culture for disinfection studies}

The initial log densities (LD) of the two species as monocultures were compared to the two species grown 
together as a co-culture (Table 1). The LDs of FS-3 and RB-8 monocultures were not statistically different from each other for the chemostat and the tubing reactor effluent samples (p-values $>0.05$ ), but there was a difference between the LDs in the biofilm samples for FS-3 and RB-8 (p-value < 0.001). The cell numbers were slightly higher for cultures containing only RB-8. FS-3 as a monoculture compared to FS-3 in a dual culture only resulted in significantly lower LDs for the monoculture in the biofilm samples (p-value < 0.001). RB-8 as a monoculture biofilm had significantly higher LDs when compared to RB-8 in the dual species biofilm (p-value $<0.001$ ) while the chemostat and tubing reactor effluent samples were similar at the $5 \%$ level.

Species distribution differences were reflected in the LDs of the co-culture. Both species were co-inoculated into the same reactor and grown for $48 \mathrm{~h}$ (chemostat) or 4 days (biofilm and biofilm reactor effluent). FS-3 was the most abundant species in all 3 sample types (chemostat, tubing reactor effluent, and biofilm) while the ratios between the species were different in the different samples. Significant differences between the species were observed in the tubing reactor effluent and the biofilm samples (p-value $=0.004$, p-value $<$ 0.001 , respectively).

B. cepacia (FS-3) was dominant when co-cultured with $P$. aeruginosa (RB-8) when comparing the initial species distribution in the chemostat, tubing reactor effluent, and biofilm samples. B. cepacia has a slightly higher growth rate (not significantly different) than $P$. aeruginosa, but was able to establish a niche in the reactors without being out-competed even after 4 days in the tubing reactor. Simultaneously, RB-8 also continued to detach from the biofilm after 4 days.

Table 1. Starting mean $\log _{10}$ densities of B. cepacia FS-3 and $P$. aeruginosa RB-8 as monocultures and as binary cultures (co-culture of FS-3 and RB-8).

\begin{tabular}{llccc}
\hline Sample type & Species & Mean & SD & n \\
\hline CS & FS-3 & 7.03 & 0.06 & 4 \\
& RB-8 & 7.07 & 0.58 & 4 \\
& DL FS-3 & 6.48 & 0.74 & 4 \\
TRE & DL RB-8 & 6.29 & 0.19 & 4 \\
& FS-3 & 6.96 & 0.29 & 4 \\
& RB-8 & 7.21 & 0.57 & 3 \\
& DL FS-3 & 7.22 & 0.20 & 3 \\
BF & DL RB-8 & 5.41 & 0.29 & 3 \\
& FS-3 & 6.98 & 0.06 & 6 \\
& RB-8 & 7.44 & 0.22 & 5 \\
& DL FS-3 & 7.43 & 0.10 & 7 \\
& DL RB-8 & 6.12 & 0.22 & 7 \\
\hline
\end{tabular}

Note: One SD is shown. $\mathrm{CS}=$ chemostat; TRE $=$ tubing reactor effluent; $\mathbf{B F}=$ biofilm; DL = dual (species in co-culture); $\mathrm{SD}=$ one standard deviation; $\mathrm{n}=$ number of replicates.

\section{Disinfection of monocultures}

$\log _{10}$ reductions after addition of incrementally increasing doses of chlorine dioxide were recorded for each sample type (chemostat, tubing reactor effluent, and biofilm) and each species scenario (FS-3, RB-8, and binary culture) (Figure 1).

Chemostat samples of the FS-3 monoculture were more susceptible to chlorine dioxide disinfection compared to tubing reactor effluent although the differences were not statistically significant when all doses of chlorine dioxide were compared (p-value > 0.05 ). Mean $\log _{10}$ reductions for RB-8 in the chemostat and detached clusters were very similar to each other (p-value $=0.99)$. The biofilms with FS-3 and RB-8 were more tolerant to disinfection compared to the other 2 sample types (chemostat and tubing reactor effluent) with mean $\log _{10}$ reductions at least 2 logs below the $\log _{10}$ reductions of the chemostat and detached clusters (p-values $<0.001$ ). The RB-8 biofilm displayed very low $\log _{10}$ reductions at low doses $(0.5,1.0,1.5$, and 2.0$)$ and was eventually killed with $10 \mathrm{ppm}$ of chlorine dioxide. FS-3 biofilms were more

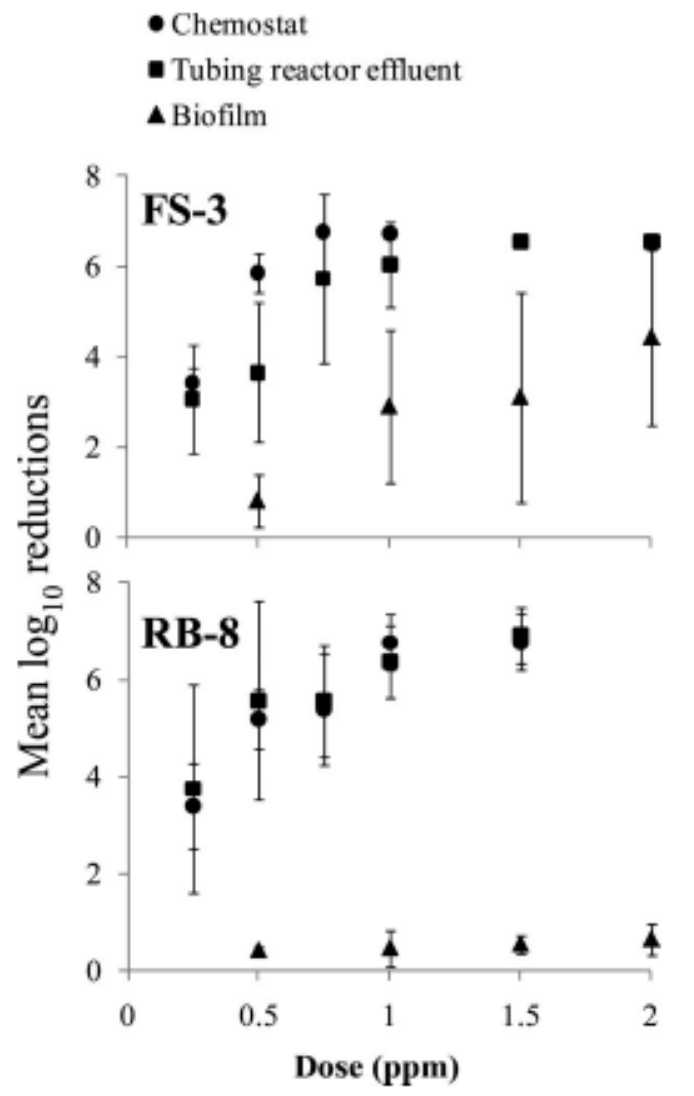

Figure 1. Mean $\log _{10}$ reductions of $B$. cepacia FS-3 and $P$. aeruginosa RB-8 monocultures in the chemostat, the tubing reactor effluent and the biofilm. The bars represent one SD $(\mathrm{n} \geq 3)$. 
susceptible to the disinfectant at these low doses although complete killing was also achieved with $10 \mathrm{ppm}$ (Figure 2).

When comparing both species within one sample type there were no significant differences in the $\log _{10}$ reductions (p-values $>0.05$ ) in the chemostat or tubing reactor effluent sample. However, the $\log _{10}$ reductions for FS-3 and RB-8 in the biofilm samples were significantly different over all treatment doses, with FS-3 being more susceptible (p-value $<0.001$ ).

\section{Disinfection of binary cultures}

When FS-3 and RB-8 were co-inoculated into the chemostat or tubing reactor and grown together, CFUs could be counted separately due to differential colony morphologies on R2A. This allowed for the calculation of separate $\log _{10}$ reductions and comparison of the two species with each other and also with the same species in the single species scenario.

The mean $\log _{10}$ reduction patterns for the two species grown together after disinfection were similar to each other although the starting cell densities were lower for RB-8 (Figure 3, also see Table 1 for comparison). Tubing reactor effluent samples were generally more susceptible to chlorine dioxide than the chemostat samples when both species were grown together, but the differences were not significant (p-value $=0.07$ ). The biofilm $\log _{10}$ reductions were significantly lower than the chemostat and detached cluster $\log _{10}$ reductions for both species (p-values < 0.001).

\section{Comparison between monocultures and binary cultures}

Generally, FS-3 and RB-8 had lower $\log _{10}$ reductions when grown in co-culture samples, meaning that single species cultures were more easily disinfected (Figure 4).

RB-8 in the dual species scenario has significantly lower $\log _{10}$ reductions for the chemostat and the

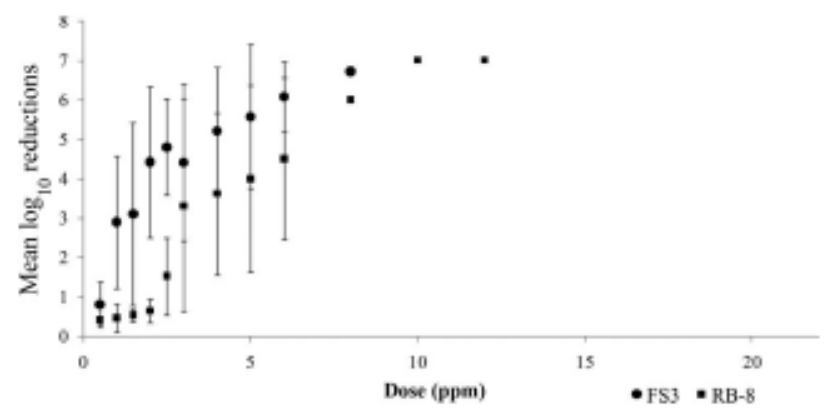

Figure 2. Mean $\log _{10}$ reductions of $B$. cepacia FS-3 and $P$. aeruginosa RB-8 as monocultures in the biofilm. The bars represent one $\mathrm{SD}(\mathrm{n} \geq 3)$. tubing reactor effluent than the single species cultures (p-values $<0.001$ ) but there was no significant difference for the biofilm samples of single and dual RB-8 (p-value $=0.80)$ despite the initial high tolerance of the single species RB-8 biofilm at low doses. FS-3 was also more tolerant when grown in co-culture and displayed significantly lower $\log _{10}$ reductions in the chemostat samples (p-value $<0.001)$ and biofilm samples than the single species FS-3 (p-value $=0.005$ ) but no significant differences were found in tubing reactor effluent samples $(\mathrm{p}$-value $=1.0)$.

\section{Disinfection of homogenized aliquots}

Aliquots of chemostat, tubing reactor effluent, and biofilm samples were shear homogenized for $1 \mathrm{~min}$ prior to treatment with chlorine dioxide. Untreated controls were homogenized to compare the initial $\log _{10}$ densities to non homogenized and untreated control samples. No significant differences were found between the homogenized and non homogenized initial $\log _{10}$ densities (p-values > 0.28) (Figure 5).

Homogenization of chemostat samples slightly increased susceptibility in all species types (FS-3,

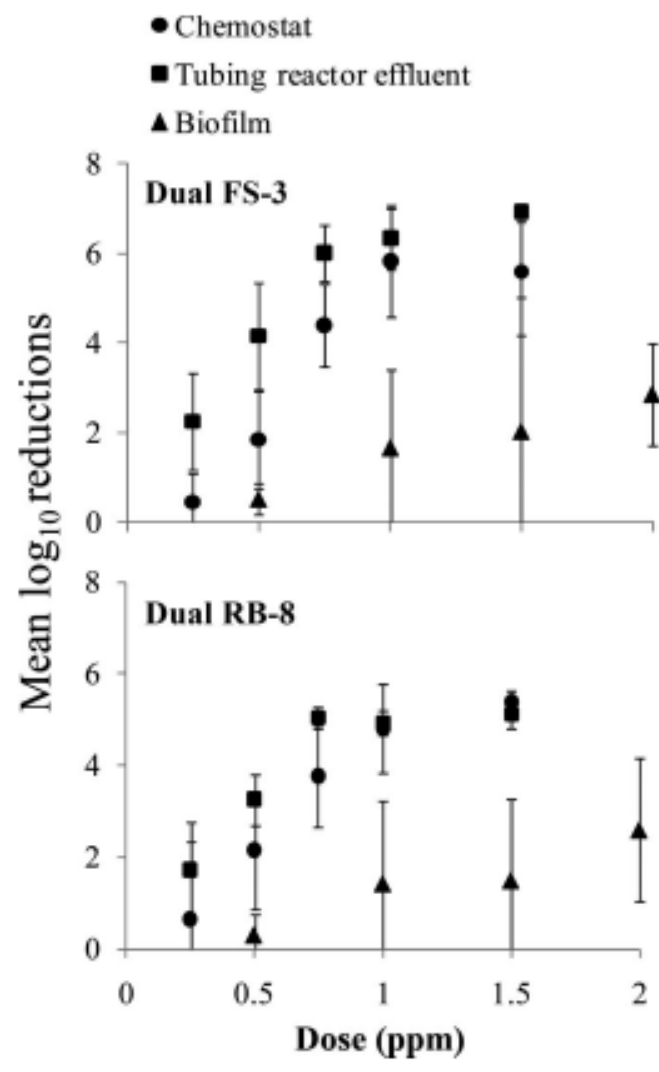

Figure 3. Mean $\log _{10}$ reductions of $B$. cepacia FS-3 and $P$. aeruginosa RB-8 as dual cultures in the chemostat, the tubing reactor effluent and the biofilm. The bars represent one SD $(n \geq 3)$. 

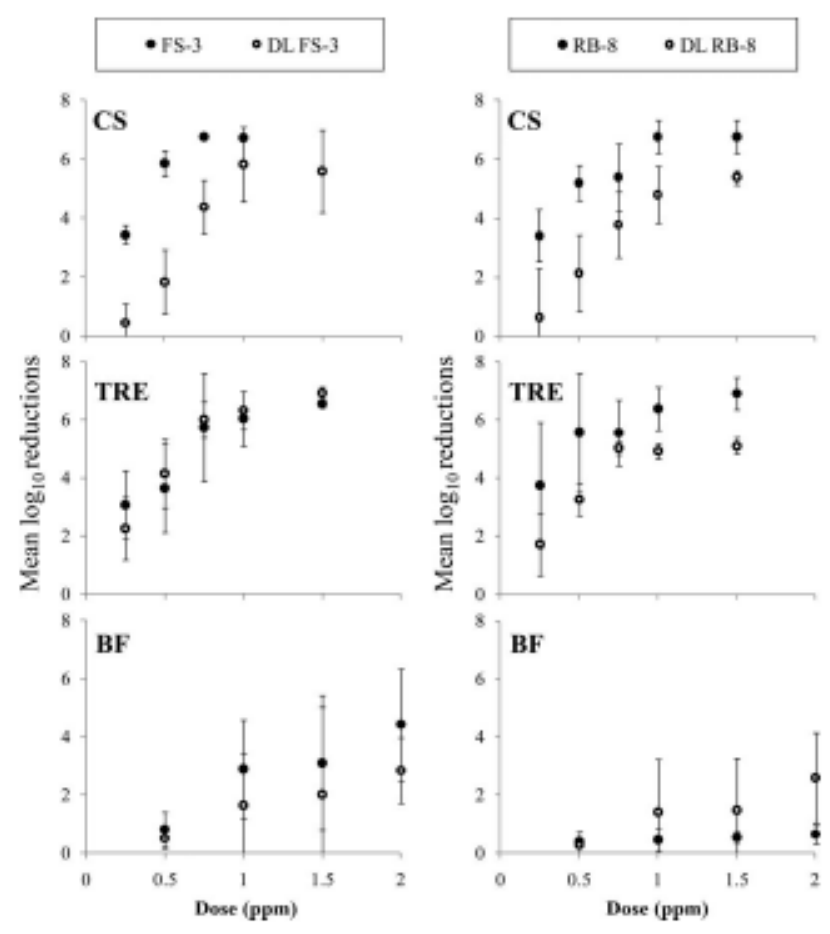

Figure 4. Mean $\log _{10}$ reductions of $B$. cepacia FS-3 and $P$. aeruginosa RB-8 as monocultures and binary cultures in comparison. Bars represent one SD $(n \geq 3)$. DL $=$ dual (species in co-culture).

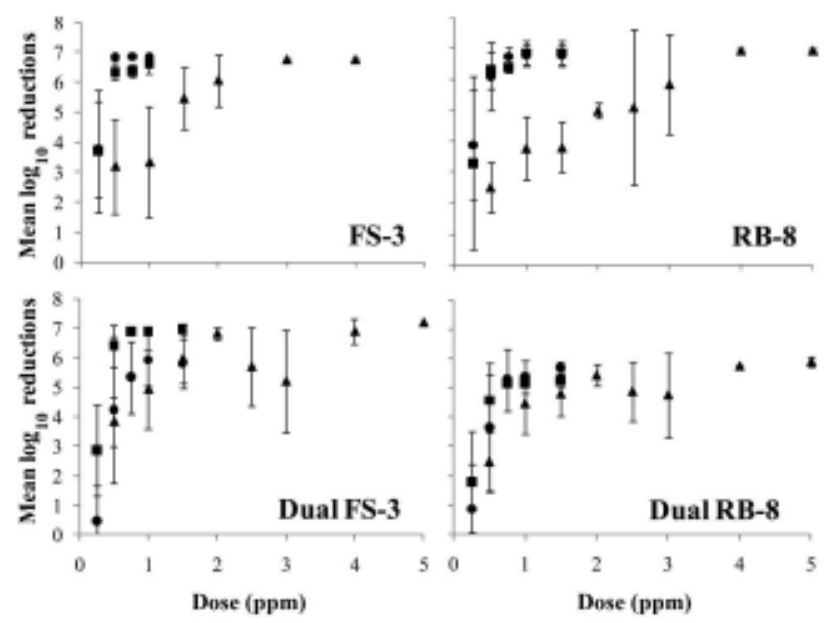

- = Chemostat; $\mathbf{-}=$ Tubing reactor effluent; $\boldsymbol{\Delta}=$ Biofilm

Figure 5. Mean $\log _{10}$ reductions of homogenized B. cepacia FS-3 and $P$. aeruginosa RB-8 as monocultures and dual cultures in the chemostat, the tubing reactor effluent and the biofilm. The bars represent one SD $(n>3)$.

RB-8 and co-culture) with significant susceptibility increases for RB-8 and dual RB-8 (p-values $<0.02$ ). None of the tubing reactor effluent samples increased significantly in susceptibility across all doses after homogenization while FS-3 and dual FS-3 in the tubing reactor effluent were significantly more

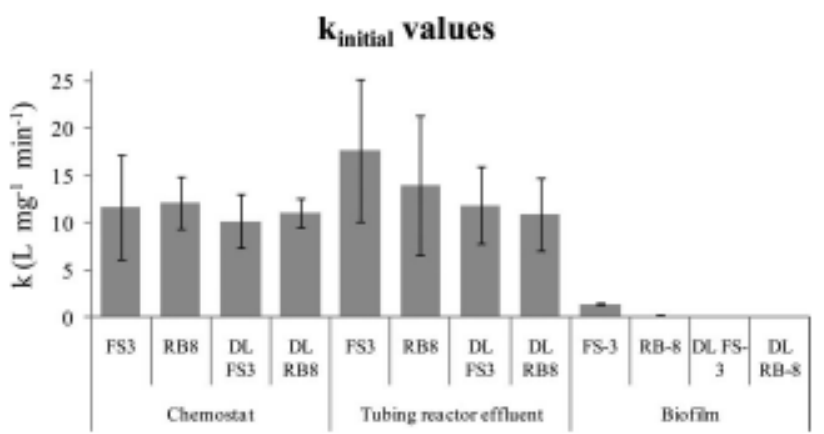

Figure 6. $k$ values for the first minute $\left(k_{\text {initial }}\right)$ of disinfection after the addition of chlorine dioxide for the chemostat, the tubing reactor effluent, and the biofilm for all 4 species scenarios ( $B$. cepacia FS-3 and $P$. aeruginosa RB-8 as monocultures and as dual cultures). Error bars represent one $\mathrm{SD}(\mathrm{n} \geq 3)$. $\mathrm{DL}=$ dual (species in co-culture).

susceptible when treated with $0.5 \mathrm{ppm}$ (p-values < $0.001)$. As expected, biofilm samples of all species were significantly more susceptible to chlorine dioxide treatment across all doses after biofilm has been extruded from the tubing, vortexed, and shear homogenized (p-values < 0.01) (Figure 5).

\section{Disinfection rates ( $k$ values)}

Using broken line regression, the concentration over time $(\mathrm{Ct})$ graphs were analyzed to determine the two different linear disinfection rates ( $\mathrm{k}$ values). The first $\mathrm{k}$ value $\left(\mathrm{k}_{\text {initial }}\right)$ describes the disinfection reaction rate of the first minute after addition of chlorine dioxide. Initially, the $\log _{10}$ reductions were high and then decreased considerably after $2 \mathrm{~min}$. The remaining disinfection reaction (after minute 1 ) is described by the second $\mathrm{k}$ value $\left(\mathrm{k}_{\text {end }}\right)$.

Most of the killing of cells occurred within the first 2 min after addition of chlorine dioxide. Disinfection rates $\left(k_{\text {initial }}\right)$ were very similar in the chemostat and tubing reactor effluent samples (p-values $>0.93$ ), indicating that similar $\log _{10}$ reductions occurred within the same time period for all 4 species scenarios and both sample types (Figure 6). The dual species FS-3 and RB-8 resulted in a slightly lower $k_{\text {initial }}$ than the single species, but there were no statistically significant differences for any of the species or sample types (pvalues $>0.05$ ). The biofilm $k_{\text {initial }}$ were significantly lower than the $\mathrm{k}_{\text {initial }}$ for all chemostat and tubing reactor effluent samples regardless of species (pvalues $<0.03$ ), indicating that the $\log _{10}$ reductions within the first minute of disinfection were much lower for all tested biofilms.

The $\mathrm{k}_{\text {end }}$ values indicate the disinfection rate from minute 2 to minute 30 . Since most of the killing occurred within the first $2 \mathrm{~min}$, the $k_{\text {end }}$ were 
significantly decreased, ranging from $0.11 \mathrm{mg}^{-1} \mathrm{~min}^{-1}$ to approximately $0.31 \mathrm{mg}^{-1} \mathrm{~min}^{-1}$ compared to the $k_{\text {initial }}$ that ranged from $10 \mathrm{lmg}^{-1} \mathrm{~min}^{-1}$ to $18 \mathrm{lmg}^{-1}$ $\min ^{-1}$ (Figure 7). The $k_{\text {end }}$ of the two dual species in the tubing reactor effluent were slightly higher than the other $\mathrm{k}_{\text {end }}$ values although no statistically relevant difference could be found. The $\mathrm{k}_{\text {end }}$ values were not significantly different from each other for any of the species or sample types (after Benjamini-Hochberg correction for false discovery) due to the high variability of the data.

\section{Disinfection of homogenized control samples ( $k$ values)}

Shear homogenization of aliquots of samples resulted in significantly higher $\mathbf{k}_{\text {initial }}$ in the biofilm samples for

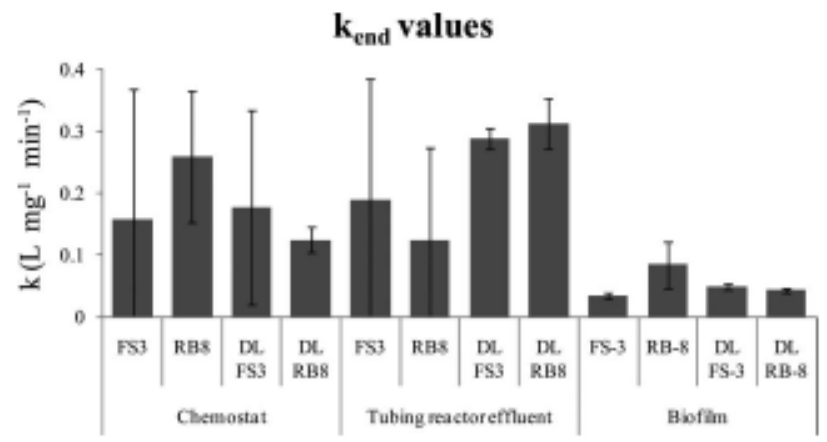

Figure 7. $\mathbf{k}$ values for minute 2 to minute $30\left(\mathrm{k}_{\text {end }}\right)$ of disinfection after the addition of chlorine dioxide for the chemostat, the tubing reactor effluent, and the biofilm for all 4 species scenarios. (FS-3 and RB-8 as monocultures and as a dual culture). Error bars represent one $\mathrm{SD}(\mathrm{n} \geq 3)$. $\mathrm{DL}=$ dual (species in co-culture).

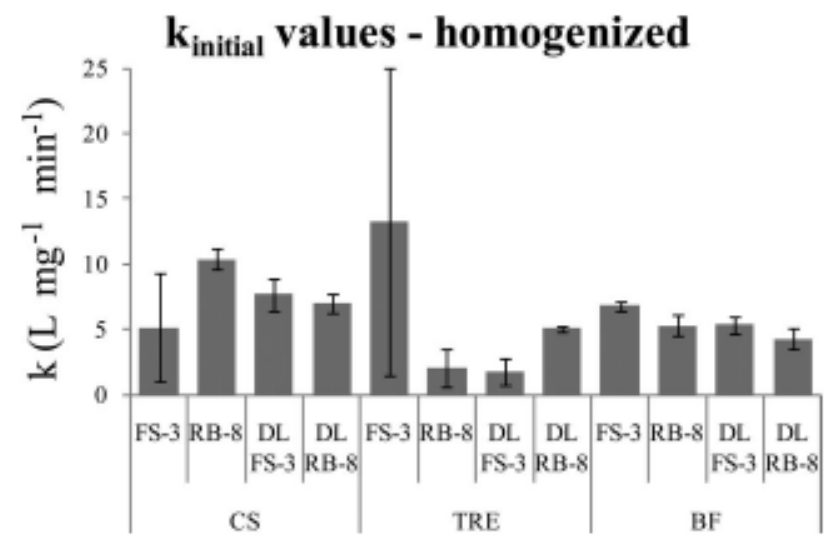

Figure 8. $\mathbf{k}$ values of homogenized samples for the first minute $\left(\mathrm{k}_{\text {initial }}\right)$ of disinfection after the addition of chlorine dioxide for the chemostat, the tubing reactor effluent, and the biofilm for all 4 species scenarios (B. cepacia FS-3 and $P$. aeruginosa RB-8 as monocultures and as dual cultures). Error bars represent one SD ( $\mathrm{n} \geq 3$ ). $\mathrm{DL}=$ dual (species in co-culture). all 4 species types (p-values $<0.018$ ). This indicates that homogenization makes biofilm cells more susceptible to disinfection (Figures 8 and 9).

Surprisingly, for homogenized chemostat and tubing reactor effluent samples, $\mathrm{k}_{\text {initial }}$ did not increase, but instead decreased by $3.731 \mathrm{mg}^{-1} \mathrm{~min}^{-1}$ for chemostat samples and $8.10 \mathrm{lmg}^{-1} \mathrm{~min}^{-1}$ for tubing reactor effluent samples on average for all species. Homogenization of the co-culture led to significantly increased susceptibility in the tubing reactor effluent for the dual FS-3 (p-value $=0.014$ ) and in the chemostat for dual RB-8 (p-value $=0.02$ ) with the $\mathrm{k}_{\text {initial }}$ being lower for homogenized samples.

The $\mathrm{k}_{\text {end }}$ values, on the other hand increased by $0.461 \mathrm{mg}^{-1} \mathrm{~min}^{-1}$ for chemostat samples and 0.40 for tubing reactor effluent samples on average for all species. The $\mathrm{k}_{\text {end }}$ values increased for all chemostat samples after homogenization (p-values $<0.029$ ), meaning that more inactivation occurred after $2 \mathrm{~min}$ than in the non homogenized samples. In the coculture, dual FS-3 and dual RB-8 the $\mathrm{k}_{\text {end }}$ increased significantly in the tubing reactor effluent samples after homogenization as well ( $\mathrm{p}$-values $<0.02$ ). None of the biofilm samples or single species FS-3 and RB- 8 tubing reactor effluent $k_{\text {end }}$ increased significantly after homogenization (p-values > 0.11) (Figure 10).

\section{Discussion}

\section{Initial cell numbers}

B. cepacia (FS-3) was dominant when co-cultured with $P$. aeruginosa (RB-8) when comparing the initial species distribution in chemostat, tubing reactor effluent, and biofilm samples (Table 1). B. cepacia

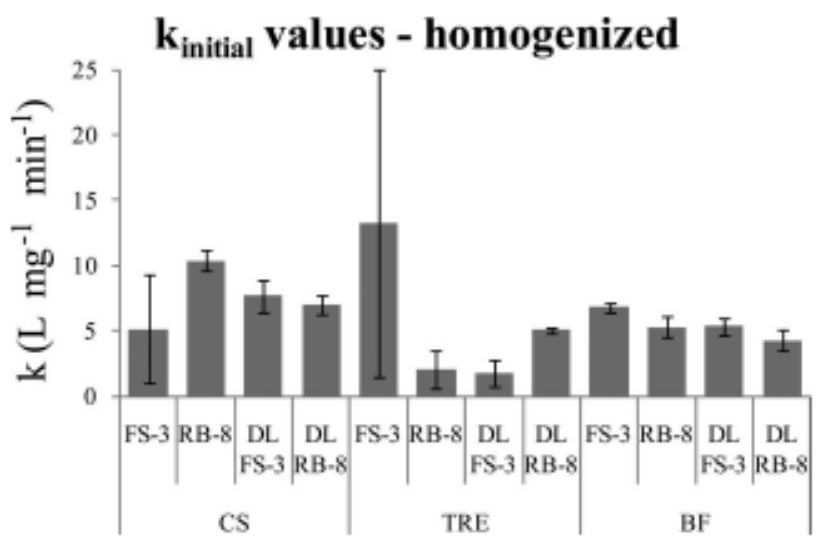

Figure 9. $\mathbf{k}$ values of homogenized samples for minute 2 to minute $30\left(\mathrm{k}_{\text {end }}\right)$ of disinfection after the addition of chlorine dioxide for the chemostat, the tubing reactor effluent, and the biofilm for all 4 species scenarios (B. cepacia FS-3 and $P$. aeruginosa RB-8 as monocultures and as dual cultures). Error bars represent SD $(n \geq 3)$. DL $=$ dual (species in coculture.) 


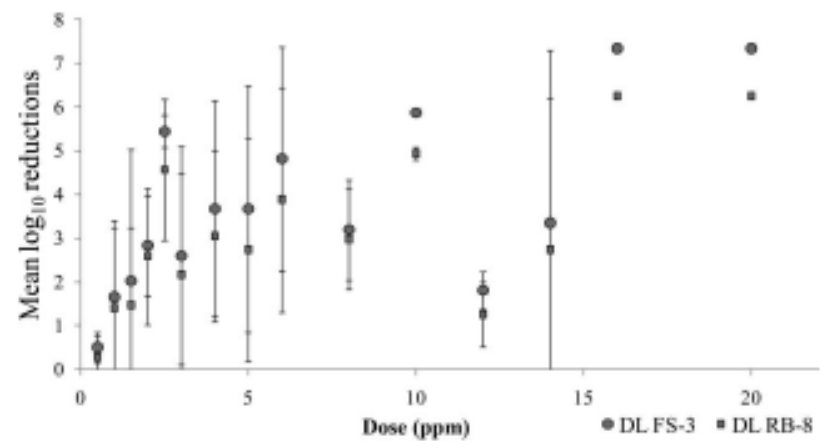

Figure 10. Mean $\log _{10}$ reductions of $B$. cepacia $\mathrm{FS}-3$ and $P$. aeruginosa RB-8 as a dual (DL) biofilm culture. The bars represent one SD $(n \geq 3)$.

has a slightly higher growth rate (not significantly different) than $P$. aeruginosa, but $P$. aeruginosa was able to establish a niche in the reactors without being out-competed even after 4 days in the tubing reactor. Simultaneously, RB-8 also continued to detach from the biofilm after 4 days. This is not surprising, since other studies have shown that growth rate is not the sole predictor of population densities and species distributions in multi-species cultures (Banks and Bryers 1991; Komlos et al. 2005).

FS-3 and RB- 8 have been tested for interspecies competition via the production of substances that impair the disinfectant susceptibility of the other species (Behnke et al. 2011). In the tests, spent medium (supernatant) cell-free extract of an FS-3 culture added to a RB-8 culture did not increase the susceptibility of a RB-8 chemostat culture to disinfection or vice versa compared to a control with PBS. Similarly, cell-free extracts of RB-8 did not affect the disinfection susceptibilities of FS-3. In addition, auto-aggregation and co-aggregation tests showed no interactions between the species (Behnke et al. 2011). All cell cultures from the chemostat and the tubing reactor effluent were standardized to $7 \log _{10}$ by dilution with buffer, while biofilm $\log _{10}$ densities were adjusted by cutting the tubing into 1 to $1.5 \mathrm{~cm}$ long pieces of the silicone tubing before submerging them into $10 \mathrm{ml}$ of buffer. Disinfection efficacy has been shown to be dependent on initial cell densities (Xu et al. 1995) and statistical analyses indicate that starting cell LDs were comparable for the performed tests.

\section{Monocultures}

FS-3 and RB-8 were individually grown in chemostats and tubing reactors. Planktonic cell samples were taken from the chemostat while attached and detached biofilm were harvested from the tubing reactor. After exposure to chlorine dioxide and neutralization of the samples, $\log _{10}$ reductions were assessed for both species in the three sample types. No significant differences between the $\log _{10}$ reductions between the chemostat and tubing reactor effluent samples were found for either species. The biofilm samples were significantly different from both the chemostat and effluent samples and this applied to both species. These results indicate that detached clusters were more similar to chemostat cells than biofilm cells; this contradicts findings by Rollet et al. (2009) who suggested a transitional phenotype for detached cells in the first hours after detachment. Disinfection experiments in this work were always performed within $1 \mathrm{~h}$ of sample collection so that the proposed transitional phenotype should still be expressed. The phenotypical switch from biofilm to planktonic state may occur much faster than initially proposed or it is possible that phenotype plays no role in protection from chlorine dioxide disinfection in the detached biofilm particles.

Interestingly, RB-8 biofilms were very tolerant to chlorine dioxide $\left(\log _{10}\right.$ reductions $\left.<0.5\right)$ below the concentration of $1 \mathrm{ppm}$ while the FS-3 and binary biofilm responded to these low concentrations with higher $\log _{10}$ reductions.

\section{Binary cultures}

FS-3 and RB-8 were co-inoculated into the chemostat and tubing reactor to grow binary cultures. Due to the fact that both species resulted in distinct colony morphologies, CFUs could be counted separately for FS-3 and RB-8 and separate log reductions were calculated. The $\log _{10}$ reduction patterns of the two species grown in binary cultures were very similar to each other although the starting LDs for RB-8 were lower. Lindsay et al. (2002) have previously reported this behavior for binary cultures and concluded that cocultured bacteria influence each other's disinfection susceptibilities and attachment characteristics. In this study the beneficial relationship between the two species was seen in biofilm samples as well as chemostat and tubing reactor effluent samples. However, this is not universal. Previous work using these same two organisms showed that co-culture in a chemostat resulted in decreased survival after a chlorine challenge (Behnke et al. 2011). These results suggest that the interaction between species will depend on the growth conditions and the disinfectant used.

In monocultures, planktonic cells were more susceptible or equally susceptible to chlorine dioxide when compared to detached clusters. In contrast to this, detached clusters from binary biofilms were more susceptible than chemostat cells although there was no statistically significant difference. A multitude of mechanisms and conditions can affect the disinfection 
tolerance of bacteria so that further testing is required to identify the factors involved here.

\section{Comparison of monocultures and binary cultures}

When directly comparing the $\log _{10}$ reductions of FS-3 and RB-8 grown as monocultures and binary cultures, increased disinfection tolerance of the species in coculture was observed. The $\log _{10}$ reductions for FS-3 in co-culture were slightly lower than the $\log _{10}$ reductions for the single species FS-3, meaning that the single species samples were less tolerant to disinfection. Similarly, RB-8 cultures were slightly more tolerant to disinfection when co-cultured with FS-3. In general, binary biofilm samples survived higher concentrations (up to $16 \mathrm{ppm}$ ) than single species biofilms (survived up to $10 \mathrm{ppm}$, data not shown). These results agree with the findings of other researchers who determined that binary cultures are more tolerant to sanitizer treatment than their single species counterparts (Leriche and Carpentier 1995; Elvers et al. 2002; Lindsay et al. 2002). Kara et al. (2006) showed that dual species biofilms of two oral bacteria were less susceptible to chlorhexadine. Using the same two organisms, subsequent work with five different antimicrobials showed increased survival for one of the species (Luppens et al. 2008). The increased survival was attributed to changes in gene expression when grown in co-culture. Cowan et al. (2000) additionally reported commensal relationships in binary biofilms that resulted in adaptive strategies and increased survival especially with respect to the spatial distribution of the species within the biofilm.

The mechanisms of increased disinfection tolerance in binary biofilms are to date mostly speculative, but studies suggest that cell to cell communication may play a role. $B$. cepacia and $P$. aeruginos $a$ strains have previously been shown to be able to communicate (McKenney et al. 1995; Riedel et al. 2001) which may explain the beneficial effect of co-culture. The presence of the second species may alter the composition and viscosity of the EPS matrix and thus the diffusivity, slowing the penetration of chlorine dioxide into the biofilm (Burmølle et al. 2006). Physiological changes may occur when two species are able to transfer conjugative plasmids and thus share protective mechanisms (Ghigo 2001) or support each other by complementing enzymes that are necessary to manage environmental challenges as observed in dental biofilms maintaining a stable pH (Shu et al. 2003).

\section{Disinfection of homogenized controls}

Before chlorine dioxide treatment, aliquots of all samples were subjected to shear homogenization. It has been shown in previous work that homogenization did not disintegrate all clusters but was able to reduce the number of larger clusters and increase the number of smaller clusters and single cells in samples (Behnke et al. 2011).

Homogenization had the most significant effect on the disinfection tolerance of the biofilm samples for all tested species. The biofilm specific tolerance against disinfection was greatly reduced, but biofilm cells remained more tolerant than chemostat or tubing reactor effluent cells (Figures 2 and 10). Since homogenized biofilm cells remained more tolerant than chemostat and tubing reactor effluent samples, a protection mechanism beyond physical biofilm-specific factors such as attachment, EPS material, close proximity of cells, and reaction-diffusion limitations may play a role in biofilm disinfection (Stewart and Raquepas 1995; Chen and Stewart 1996; Stewart 2003). However, the chemostat and tubing reactor effluent disinfection tolerance did not change as significantly as the biofilm tolerance after homogenization (p-values < 0.01 ). Differences between LRs of homogenized and unhomogenized chemostat samples were limited to RB8 (p-value $=0.02)$ and dual RB-8 $(\mathrm{p}$-value $=0.0001)$ as well as a single dose $(0.5 \mathrm{ppm})$ in the tubing reactor effluent and chemostat samples for FS-3 and dual FS-3 (p-values all $<0.09$ ).

Chlorine dioxide disinfection experiments with unhomogenized samples demonstrated that the tubing reactor effluent cells were similar to planktonic cells and different from biofilm cells with respect to $\log _{10}$ reductions. This set of control experiments with homogenized samples supports this finding because the tubing reactor effluent samples did not decrease significantly (across all doses) in tolerance after homogenization as was seen in the biofilm.

\section{Disinfection rates}

Chlorine dioxide added to cell culture samples of the chemostat and the tubing reactor effluent decayed slowly over the course of $30 \mathrm{~min}$ and no residual remained (data not shown). Most of the $\log _{10}$ reductions occurred within the first $2 \mathrm{~min}$ of the experiment with no significant subsequent reductions. As expected, based on disinfection experiments, no significant differences were found when comparing the chemostat and tubing reactor effluent $\mathrm{k}_{\text {initial }}$ for all 4 species scenarios (FS-3 single, RB- 8 single, FS-3 dual, RB-8 dual; p-values $>0.93$ ). This indicates that cells in these samples were inactivated at similar rates within the first minute of exposure to chlorine dioxide. Regardless of species, the $\mathbf{k}_{\text {initial }}$ of biofilm samples were significantly different from the chemostat and tubing reactor $\mathrm{k}_{\text {initial }}(\mathrm{p}$-values $<0.03$ ) which was also 
supported by the results of the disinfection experiments (Figures 1 and 3). Biofilm inactivation may be slowed by reaction-diffusion limitations of chlorine dioxide into the biofilm where the disinfectant is simultaneously diffusing into the biofilm and reacting with biofilm constituents thus protecting the cells (Stewart and Raquepas 1995).

\section{Disinfection rates of homogenized samples}

The disinfection rates of homogenized aliquots of samples reflect findings from the disinfection experiments with homogenized samples. The $\mathrm{k}_{\text {initial }}$ significantly increased when biofilms were homogenized before treatment with chlorine dioxide. Homogenization greatly decreases the influence of physical biofilmspecific properties such as the presence of EPS material, diffusion-reaction limitation, and possibly even cell to cell communication which has been demonstrated to be beneficial during disinfection challenges on biofilms (Burmølle et al. 2006).

Surprisingly, for homogenized chemostat and tubing reactor effluent samples, $\mathrm{k}_{\text {initial }}$ did not increase, but instead decreased while $\mathrm{k}_{\text {end }}$ values increased for all species. This suggests that homogenization reduces the susceptibility of the cells to chlorine dioxide during the first two minutes.

\section{Comparison with free chlorine}

Behnke et al. (2011) demonstrated that chlorine disinfection of detached clusters may be dependent on cell cluster size. Clusters containing a higher number of cells were found to be more tolerant to chlorine treatment than cells in small clusters.

Cluster distribution in the present study also varied with reactor type and species where FS- 3 chemostat samples contained $\sim 5 \%$ large clusters $(11+$ cells $)$ while the biofilm reactor effluent resulted in about $30 \%$ large clusters. The chemostat samples of RB- 8 on the other hand had about $30 \%$ large clusters while the biofilm reactor effluent had a smaller percentage of large clusters $(10 \%)$. In co-culture the percentage of large clusters was $5 \%$ in the chemostat and $10 \%$ in the biofilm reactor effluent samples. However, evidence for a relationship between the cluster sizes and the disinfection efficacy could not be found.

In disinfection studies with chlorine higher doses of the chemical are required to inactivate samples than are needed with chlorine dioxide, while the highest log reductions of cultures with chlorine dioxide occur at a slower rate $(2 \mathrm{~min})$ than the disinfection kinetics observed in experiments with chlorine $(1 \mathrm{~min})$. These differences can be attributed to the different modes of biocidal action and the reactivity of the two compounds with constituents of the biofilm matrix. Independent of the disinfecting agent, biofilms were always significantly more tolerant to treatment than planktonic cells or detached clusters. Other studies confirmed that mature drinking water biofilms were reduced by only minimal $\log _{10}$ reductions ( 0.5 to 1.5 ) after a single dose of chlorine dioxide (Gagnon et al. 2005), also suggesting protection and that several doses may be required to achieve higher log reductions in drinking water biofilms.

\section{Conclusions}

In this study, detached biofilm clusters were found to have similar $\log _{10}$ reductions and disinfection rates to chemostat cells and were very different from biofilm cells.

Binary cultures were less susceptible than single species cultures for all three sample types (chemostat, biofilm, and detached biofilm particles). This finding suggests that the two strains promoted overall disinfection survival and led to similar disinfection patterns, as previously described by Lindsay et al. (2002) and Luppens et al. (2008). Multiple studies have found similar results with binary cultures (Leriche and Carpentier 1995; Elvers et al. 2002; Lindsay et al. 2002), but mechanisms for this increased tolerance have not been sufficiently studied. Researchers have suggested a change in the EPS matrix constituents due to the presence of a second species can lead to viscosity and permeability changes (Skillman et al. 1999; Burmølle et al. 2006). Allison and Matthews (1992) found viscosity changes in Burkholderia cepacia and Pseudomonas aeruginosa dual biofilms that reduced diffusion of antibiotics which may also slow disinfection with chlorine dioxide.

\section{Acknowledgements}

The authors would like to thank Albert E. Parker for statistical support and training. In addition, they would like to thank Dawn Woodall, Denise Donoghue, and David Oliver at Unilever, Port Sunlight, UK, for their support. This work was supported by Unilever UK Central Resources Limited. Thanks are also due to BASF for providing the chlorine dioxide tablets used in this study.

\section{References}

Allison DG, Matthews MJ. 1992. Effect of polysaccharide interactions on antibiotic susceptibility of Pseudomonas aeruginosa. J Appl Bact 73:484-488.

Banks MK, Bryers JD. 1991. Bacterial species dominance within a binary culture biofilm. Appl Environ Microbiol 57:1974-1979.

Behnke S, Parker AE, Woodall D, Camper AK. 2011. Comparing the chlorine disinfection of detached biofilm clusters with sessile biofilms and planktonic cells in single and dual species cultures. Appl Environ Microbiol 77: 176-7184. 
Benarde MA, Snow WB, Olivieri VP, Davidson B. 1967. Kinetics and mechanism of bacterial disinfection by chlorine dioxide. Appl Microbiol 15:257-265.

Benjamini Y, Hochberg Z. 1995. Controlling the false discovery rate: a practical and powerful approach to multiple testing. J Roy Stat Soc 57:289-300.

Burmølle M, Webb JS, Rao D, Hansen LH, Sørensen SJ, Kjelleberg S. 2006. Enhanced biofilm formation and increased resistance to antimicrobial agents and bacterial invasion are caused by synergistic interactions in multispecies biofilms. Appl Environ Microbiol 72:3916-3923.

Chen X, Stewart PS. 1996. Chlorine penetration into artificial biofilm is limited by a reaction-diffusion interaction. Environ Sci Technol 30:2087-2083.

Chick H. 1908. An investigation of the laws of disinfection. J Hyg 8:92-158.

Costerton JW, Lewandowski Z, Caldwell DE, Korber DR, Lappin-Scott HM. 1995. Microbial biofilms. Annu Rev Microbiol 49:711-745.

Cowan SE, Gilbert E, Liepmann D, Keasling JD. 2000. Commensal interactions in a dual-species biofilm exposed to mixed organic compounds. Appl Environ Microbiol 66:4481-4485.

Davies D. 2003. Understanding biofilm resistance to antibacterial agents. Nat Rev Drug Discov 2:114-122.

Davison WM, Pitts B, Stewart PS. 2010. Spatial and temporal patterns of biocide action against Staphylococcus epidermidis biofilms. Antimicrob Agents Chemother 54:2920-2927.

DeBeer D, Srinivasan R, Stewart PS. 1994. Direct measurement of chlorine penetration into biofilms during disinfection. Appl Environ Microbiol 60:4339-4344.

Donlan RM, Costerton JW. 2002. Biofilms: survival mechanisms of clinically relevant microorganisms. Clin Microbiol Rev 15:167-193.

Elvers KT, Leeming K, Lappin-Scott HM. 2002. Binary and mixed population biofilms: Time-lapse image analysis and disinfection with biocides. J Ind Microbiol Biot 29: 331-338.

Fux CA, Wilson S, Stoodley P. 2004. Detachment characteristics and oxacillin resistance of Staphylococcus aureus biofilm emboli in an in vitro catheter infection model. J Bacteriol 186:4486-4491.

Gagnon GA, Rand JL, O'Leary KC, Rygel AC, Chauret C, Andrews RC. 2005. Disinfectant efficacy of chlorite and chlorine dioxide in drinking water biofilms. Water Res 39:1809-1817.

Gauw RD, Emmert GL, Bubnis B, Gordon G. 1999. High resolution spectrophotometry for identification of chlorine dioxide in concentrated chlorine solutions. Talanta 50:1073-1078.

Ghigo J-M. 2001. Natural conjugative plasmids induce bacterial biofilm development. Nature 412:442-445.

Herigstad B, Hamilton M, Heersink J. 2001. How to optimize the drop plate method for enumerating bacteria. Microbiol Methods 44:121-129.

Hoigné J, Bader H. 1994. Kinetics of reactions of chlorine dioxide $(\mathrm{OClO})$ in water - I. Rate constants for inorganic and organic compounds. Water Res 28:45-55.

Hunt SM, Werner EM, Huang B, Hamilton MA, Stewart PS. 2004. Hypothesis for the role of nutrient starvation in biofilm detachment. Appl Environ Microbiol 70:74187425 .

Ingols RS, Ridenour GM. 1948. Chemical properties of chlorine dioxide. J Am Water Works Assoc 40:12071227.
Jang A, Szabo J, Hosni AA, Coughlin M, Bishop PL. 2006. Measurement of chlorine dioxide penetration in dairy process pipe biofilms during disinfection. Appl Microbiol Biotechnol 72:368-376.

Kara D, Luppens SBI, ten Cate JM. 2006. Differences between single- and dual-species biofilms of Streptococcus mutans and Veillonella parvula in growth, acidogenicity and susceptibility to chlorhexidine. Eur J Oral Sci 114:58-63.

Komlos J, Cunningham AB, Camper AK, Sharp RR. 2005. Effect of substrate concentration on dual-species biofilm population densities of Klebsiella oxytoca and Burkholderia cepacia in porous media. Biotechnol Bioeng 93:434-442.

Leriche V, Carpentier B. 1995. Viable but non-culturable Salmonella typimurium in single and binary species biofilms in response to chlorine treatment. J. Food Protect 58:1186-1191.

Lindsay D, Brozel VS, Mostert JF, Von Holy A. 2002. Differential efficacy of a chlorine-dioxide containing sanitizer against single species and binary biofilms of a dairy-associated Bacillus cereus and a Pseudomonas fluorescens isolate. J Appl Microbiol 92:352-361 .

Loewen PC, Hengge-Aronis R. 1994. The role of the sigma factor sigma $\mathrm{S}$ (KatF) in bacterial global regulation. Annu Rev Microbiol 48:53-80.

Luppens SBI, Kara D, Bandounas L, Jonker MJ, Wittink FRA, Bruing O, Breit TM, ten Cate JM, Criellard W. 2008. Effect of Veillonella parvula on the antimicrobial resistance and gene expression of Streptococcus mutans grown in dual-species biofilm. Oral Microbiol Immunol 23:183-189.

Mayack LA, Soracco RJ, Wilde EW, Pope DH. 1984. Comparative effectiveness of chlorine and chlorine dioxide biocide regimes for biofouling control. Water Res 18:593-599.

McKenney D, Brown KE, Allison DG. 1995. Influence of Pseudomonas aeruginosa exoproducts on virulence factor production in Burkholderia cepacia: evidence of interspecies communication. J Bacteriol 23:6989-6992.

Møller S, Pedersen AR, Poulsen LK, Arvin E, Molin S. 1996. Activity and three-dimensional distribution of toluenedegrading Pseudomonas putida in a multispecies biofilm assessed by quantitative in situ hybridization and scanning confocal laser microscopy. Appl Environ Microbiol 62:4632-4640.

Møller S, Stemberg C, Andersen JB, Christensen BB, Ramos JL, Giskov M, Molin S. 1998. In situ gene expression in mixed-culture biofilms: evidence of metabolic interactions between community members. Appl Environ Microbiol 64:721-732.

Nielsen, AT, Tolker-Nielsen T, Barken KB, Molin S. 2000. Role of commensal relationships on the spatial structure of a surface-attached microbial consortium. Environ Microbiol 2:59-68.

Rani, SA, Pitts B, Beyenal H, Veluchamy RA, Lewandowski Z, Davison WM, Buckingham-Meyer K, Stewart PS. 2007. Spatial pattems of DNA replication, protein synthesis, and oxygen concentration within bacterial biofilms reveal diverse physiological states. J Bacteriol 189:4223-4233.

Ridenour GM, Ingols RS. 1947. Bactericidal properties of chlorine dioxide. J Am Water Works Assoc 39:561-567.

Riedel K, Hentzer M, Geisenberger O, Huber B, Steidle A, Wu H, Høiby N, Givskov M, Molin S, Eberl L. 2001. Acylhomoserine-lactone-mediated communication between Pseudomonas aeruginosa and Burkholderia cepacia in mixed biofilms. Soc Gen Microbiol 147: 3249-3262. 
Rollet C, Gal L, Guzzo J. 2009. Biofilm-detached cells, a transition from a sessile to a planktonic phenotype: A comparative study of adhesion and physiological characteristics in Pseudomonas aeruginosa. FEMS Microbiol Lett 290:135-142.

Sauer K, Camper AK, Ehrlich GD, Costerton JW, Davies DG. 2002. Pseudomonas aeruginosa displays multiple phenotypes during development as a biofilm. J Bacteriol 184:1140-1154.

Shu M, Browngardt CM, Chen Y-YM, Burne RA. 2003. Role of urease enzymes in stability of a 10 -species oral biofilm consortium cultivated in a constant-depth film fermenter. Infect Immun 71:7188-7192.

Simões M, Pereira MO, Vieira MJ. 2005. Action of a cationic surfactant on the activity and removal of bacterial biofilms formed under different flow regimes. Water Res 39:478-486.

Simões M, Simões LC, Pereira MO, Vieira MJ. 2008. Antagonism between Bacillus cereus and Pseudomonas fluorescens in planktonic systems and in biofilms. Biofouling 24:339-349.

Skillman LC, Sutherland IW, Jones MV. 1999. The role of exopolysaccharides in dual species biofilm development. J Appl Microbiol (Symp Suppl) 85:13s-18s.
Steed KA, Falkingham III JO. 2006. Effect of growth in biofilms on chlorine susceptibility of Mycobacterium avium and Mycobacterium intracellulare. Appl Environ Microbiol 72:4007-4011.

Stewart PS. 2003. Diffusion in biofilms. J Bacteriol 185:14851491.

Stewart PS, Raquepas JB. 1995. Implications of reactiondiffusion theory for the disinfection of microbial biofilms by reactive antimicrobial agents. Chem Eng Sci 50:3099 3104.

Walters MC III, Roe F, Bugnicourt A, Franklin MJ, Stewart PS. 2003. Contributions of antibiotic penetration, oxygen limitation, and low metabolic activity to tolerance of Pseudomonas aeruginosa biofilms to ciprofloxacin and tobramycin. Antimicrob Agents Chemother 47:317-323.

Wilson S, Hamilton MA, Hamilton GC, Schumann MR, Stoodley P. 2004. Statistical quantification of detachment rates and size distributions of cell clumps from wild-type (PAO1) and cell signaling mutant (JP1) Pseudomonas aeruginosa biofilms. Appl Environ Microbiol 70:58475852.

Xu X, Stewart PS, Chen X. 1995. Transport limitation of chlorine disinfection of Pseudomonas aeruginosa entrapped in alginate beads. Biotechnol Bioeng 49:93-100. 